\title{
Second sight? Ecker JL, Dumitrescu ON, Wong KY, Alam NM, Chen SK, LeGates T, Renna JM, Prusky GT, Berson DM, Hattar S (2010) Melanopsin-expressing retinal ganglion-cell photoreceptors: cellular diversity and role in pattern vision. Neuron 67:49-60
}

\author{
David Hicks \\ Received: 21 January 2011 / Accepted: 27 January 2011 / Published online: 19 February 2011 \\ (C) Springer-Verlag 2011
}

Keywords Melanopsin $\cdot$ Retinal ganglion cells

Ever since the existence of directly photosensitive retinal cells distinct from rod and cone photoreceptors exploded onto the scene some 10 years ago, the field has been one of the most fertile and exciting in vision research. It took a long time to convince a sceptical academic establishment that light detection was present in mammals even in the complete absence of rods and cones, but the definitive proof was supplied a decade ago when directly photosensitive retinal ganglion cells were identified. This specialised sub-population, representing only $1-2 \%$ of total ganglion cells, expresses a newly discovered visual pigment termed melanopsin, distantly related to the classic visual opsins in rods and cones. To sum up the numerous groundbreaking discoveries concerning this class of cell, the idea grew that whereas rods and cones subserved "image-forming" vision, in contrast the "intrinsically photosensitive retinal ganglion cells" or ipRGC subserved "non-image forming" vision. That is, their characteristics (morphology, physiology, spectral sensitivity and target projection sites within the brain) indicated they were responsible for major functions such as synchronisation of the circadian clock (located in the ventral hypothalamus) with external light cues, pupillary constriction, pineal melatonin secretion, and

\section{Hicks $(\square)$}

Département de Neurobiologie des Rythmes, CNRS UPR 3212, Institut des Neurosciences Cellulaires et Intégratives,

Université de Strasbourg,

5 rue Blaise Pascal,

67084 Strasbourg Cedex, France

e-mail: photoreceptor67@hotmail.com sleep/wake cycles. And even though it quickly became clear that ipRGC also relied upon input from the classical rod and cone circuits, these two aspects of visual processing - imageforming and non-image forming vision - were considered as largely separate.

But in such a rapidly evolving field of research, things are (still) becoming more complicated before they become simpler: recent papers such as the article by Ecker and associates [1] show that the range of functions attributable to ipRGC actually goes far beyond what was originally thought, and that use of light information on a systems level is far more pervasive than we imagined. Before going any further, let it be made clear for a medically-oriented readership that ipRGCs play important roles in health and disease, both directly and indirectly: melanopsin mutations segregate with seasonal affective disorder, some $40 \%$ of blind people have sleep problems (either insomnia or daytime somnolence), the ipRGCs have been linked to migraine and photophobia, and nightshift workers (i.e., exposed to non-natural lighting regimes) have significantly higher incidences of metabolic disorders, depression and cancer. Light exposure has even been shown to affect adrenal gland function (cortisol secretion).

But coming back to the study in question, using a genetic strategy involving high amplification of the reporter gene (either green fluorescent protein or alkaline phosphatase) the authors showed that melanopsin-containing retinal ganglion cells were more diverse (five distinct sub-types compared to the previously identified three), far more numerous (some 3-4 fold) and projected to many more areas in the brain than had been demonstrated previously. These newly described heavily innervated projection sites 
include the lateral geniculate nucleus, the principal relay centre for "conventional" retinal ganglion cells involved in image-forming vision. This observation begged the question of whether ipRGC could also be involved in imageforming vision. The authors addressed this through the use of another transgenic mouse line, engineered in such a way that rod and cone function is completely abolished, leaving the ipRGC as the only photoreceptive system. Such mice displayed visual discrimination in behavioural tasks, even if it took them around twice as long to use visual cues as the normal-sighted controls. And the proof that this was entirely mediated by melanopsin came from the use of a triple knockout animal, devoid of any photoreception. Furthermore, immunohistochemical and anatomical data supported the ability of mice relying solely on melanopsinbased vision to distinguish spatial patterning. Finally, one surprising (and little-commented) finding concerned the methodology: the authors detected direct light sensitivity in ipRGCs that had such low expression levels of melanopsin that they were undetectable by immunohistochemistry!

So, the worlds of image-forming and non-image forming vision are not as separated as was thought, and as has been mentioned above light input leads to a wide variety of physiological responses in animals and man. Indeed, studies in blind humans (lacking the classical rods and cones due to inherited retinal degeneration) had suggested several years prior to this genetic approach in mice that somehow non-image forming visual processing impinged upon conscious light perception [2] The newly discovered photosensitive system has yet to reveal many of its fascinating secrets, although maybe one shouldn't be so surprised at its far-reaching implications: available evidence indicates that these novel photoreceptors are very different from rods and cones (and from other retinal ganglion cells) in many ways - gene expression, development, morphology, biochemistry, physiology, development, and pathology (interested readers are referred to a recent review by Pierson et al. [3]). They are in fact very ancient in evolutionary terms, maybe constituting an ancestral form of light detection. Their presence in vertebrates (especially mammals) went unsuspected for many years, but they are making up for lost time.

\section{References}

1. Ecker JL, Dumitrescu ON, Wong KY, Alam NM, Chen SK, LeGates T, Renna JM, Prusky GT, Berson DM, Hattar S (2010) Melanopsin-expressing retinal ganglion-cell photoreceptors: cellular diversity and role in pattern vision. Neuron 67:49-60

2. Zaidi FH, Hull JT, Peirson SN, Wulff K, Aeschbach D, Gooley JJ, Brainard GC, Gregory-Evans K, Rizzo JF 3rd, Czeisler CA, Foster RG, Moseley MJ, Lockley SW (2007) Short-wavelength light sensitivity of circadian, pupillary, and visual awareness in humans lacking an outer retina. Curr Biol 17(24):2122-2128

3. Pierson SN, Halford S, Foster RG (2009) The evolution of irradiance detection: melanopsin and the non-visual opsins. Phil Trans R Soc B 364:2849-2865 